\title{
Perspectives of hematology oncology clinicians about integrating palliative care in oncology
}

\author{
R. Booker $M N B S c N^{*}$ S. Dunn $\mathrm{MPH}^{+}{ }^{\dagger}$ M.A. Earp $\mathrm{PhD}_{,}^{\neq}$A. Sinnarajah MD MPH, ${ }^{\dagger \ddagger \S}$ \\ P.D. Biondo $\mathrm{PhD}^{\ddagger}$ and J.E. Simon $\mathrm{MB} \mathrm{ChB}^{\dagger \neq \|}$
}

\begin{abstract}
Patients with hematologic malignancies receive palliative care (PC) less frequently and later than patients with solid tumours. We compared survey responses of hematology oncology clinicians with other oncology clinicians to better understand their challenges with providing primary PC or using secondary PC. Patients' negative perceptions of PC and limited time or competing priorities were challenges for all clinicians. Compared with other oncology clinicians, more hematology oncology clinicians perceived PC referral criteria as too restrictive $(40 \%$ vs. $22 \%, p=0.021)$ and anticipated that integrating PC supports into their practice would require substantial change ( $53 \% \mathrm{vs.} 28 \%, p=0.014$ ). This study highlights barriers that may need targeted interventions to better integrate PC into the care of patients with hematologic malignancies.
\end{abstract}

Key Words Hematologic malignancies, clinician perspectives, mixed-methods

Curr Oncol. 2020 December:27(6)313-320

www.current-oncology.com

\section{INTRODUCTION}

There is a growing body of literature demonstrating that timely palliative care (PC), in the context of advanced cancer, is associated with a number of favourable outcomes, including: improved symptom management, better prognostic understanding, improved quality of life for patients and caregivers, and even improved patient survival in some contexts $^{1-5}$. However, it has been well established that patients with hematologic malignancies do not routinely receive $\mathrm{PC}^{6-8}$. A systematic review ${ }^{6}$ of twenty-four studies found that patients with hematologic malignancies were less likely than patients with solid tumours to receive specialist PC consultation $(p<0.0001)$. In addition, end-of-life (EOL) quality measures are typically worse in patients with hematologic malignancies than in patients with solid tumours $^{8-10}$. Hui et al. ${ }^{7}$ reported that, in the last 30 days of life, patients with hematologic malignancies, compared with those having solid tumours, were more likely to have prolonged ( $>14$ days) hospitalizations (38\% vs. $7 \%, p<0.001$ ), to have more intensive care unit admissions (39\% vs. $8 \%$, $p<0.001$ ), and to die in a hospital (33\% vs. $4 \%, p<0.001)$.

There are many potential reasons why patients with hematologic malignancies are not being routinely referred to PC, including the following: more disease-modifying therapies that can be used until very close to death, systems issues (lack of policies, processes, or lack of resources) ${ }^{10-13}$, clinician reluctance due to fears of evoking anxiety or sadness in patients ${ }^{14,15}$, and patient and caregiver perceptions that PC is associated with EOL care ${ }^{16,17}$.

Oncologists play an integral role in the integration of $\mathrm{PC}$, and thus it is imperative to understand their perspectives on using PC. ${ }^{13}$ The Lancet Oncology Commission report on the integration of PC in oncology reviewed a number of studies exploring clinician attitudes about PC integration in oncology ${ }^{16}$. Few of those studies (and none Canadian) focused on the differences between hematology oncology clinicians (HOCs) and other solid-tumour oncology clinicians (OCs) ${ }^{15,18-20}$.

\section{PURPOSE}

This survey was part of a larger program of research [Palliative Care Early and Systematic (PaCES) $]^{21}$ on the integration of early PC in cancer. The purpose was to characterize the barriers to integration of early PC for oncology clinicians. Data collected were previously analyzed for the entire cohort of oncology clinicians by Watanabe et $a l .^{22}$. The 
primary objective of the study was to gain an understanding of the behavioural influencers that affect when and how oncology clinicians refer patients with advanced cancer to PC services. This paper focuses on the differences and similarities between HOCs and oCs.

\section{METHODS}

\section{Instrument}

The Palliative Care Early and Systematic Expanded Oncology Survey (supplemental Appendix 1) was adapted from a survey we previously developed ${ }^{11}$. It consists of 33 questions, based on Michie's Theoretical domains framework ${ }^{11}$, pertaining to challenges oncology providers encounter in the following domains: making PC referrals, working with PC, and attending to the PC needs of outpatients. Quantitative questions used a 7-point Likert-type scale. The survey included 7 demographic questions about the respondent, including professional role, discipline, location of work, years in practice, gender, frequency of working with patients with advanced cancer, and tumour group or groups worked with. Respondents who worked with more than one tumour group were asked to choose one tumour group to use as their lens as they answered the remaining survey questions. The survey also included 5 open-ended questions.

\section{Sample}

The identified target population was oncology clinicians in Alberta, including physicians, nurses, radiation therapists, and allied health professional, who serve patients with advanced cancer in outpatient settings in cancer centres. Exclusion criteria included the inability to read and understand English, as the survey was available in English only, and not working in a role with outpatients who have advanced cancer.

\section{Survey Process}

The Web-based application REDCap (Research and Electronic Data Capture, version 7.2) ${ }^{23}$ was used to administer the survey. The survey link was sent by e-mail, on 3 separate occasions, via provincial tumour groups' internal distribution lists as well as by CancerControl Alberta's comprehensive email distribution list of all oncology clinicians in Alberta. The survey was also advertised in the provincial cancer organization's newsletter. Data collection occurred from November 2017 to January 2018. Study participation was voluntary; implied consent was obtained with survey completion. Responses were confidential and anonymized. The Health Research Ethics Board of Alberta approved the study (HREBA.CC-17-0354).

\section{Data Analysis}

Demographic and survey response data were summarized using standard descriptive statistics. Response frequencies were used to ascertain clinicians' top perceived concerns. Survey responses from HOCs and ocs were compared using the Fisher exact test (2-sided). Statistics were computed usingthe IBM SPSS Statistics software application (version 25: IBM, Armonk, NY, U.S.A.). Conventional content analysis $^{24}$ was used to analyze the responses to the open-ended questions, so as to derive concepts or categories to describe a particular phenomenon ${ }^{25}$. Three team members (JES, MAE, SD) analyzed the data; each individual began by inductively and iteratively coding for primary themes. The coders subsequently met and achieved consensus on the final coding structure.

\section{RESULTS}

\section{Quantitative Results}

The survey response rate was $44 \%$ (366 respondents out of an estimated 824 e-mail recipients). Respondents were excluded if they indicated that they did not work with outpatients with advanced cancer $(n=26)$ or indicated that they worked in a professional role that does not include outpatient care of patients with cancer $(n=34)$, including research only $(n=6)$, clinical trials only $(n=4)$, systems analyst $(n=1)$, inpatient only $(n=7)$, and clerical $(n=16)$. The final sample size was 263 (Table I), including 30 HOCs and 233 ocs.

The top two challenges identified by HOCs and ocs included patients' negative perceptions of palliative care $67 \%$ for HOCs, $63 \%$ for OCs, $p=0.477$; Table II) and limited time or competing needs (64\% for HOCs, $64 \%$ for OCs, $p=0.614$ ). Compared with OCs, HOCs more frequently reported that PC referral criteria were too restrictive ( $40 \%$ vs. $22 \%, p=0.021$ ) and that they would personally have to make substantial practice changes to incorporate early PC supports (53\% vs. $28 \%, p=0.014)$. While the Fisher exact test revealed significant differences between HOCs and ocs for the survey question asking respondents to indicate whether they felt that making referrals to PC was challenging because of too few $P C$ providers in their region, review of the results revealed that the differences between the groups were not whether respondents agreed or disagreed with the statement, but rather the number of respondents who selected the neutral response. In particular, $43 \%$ of HOCs agreed that there are too few providers, and $43 \%$ of HOCs disagreed that there are too few providers. Similarly, $38 \%$ of ocs agreed that there are too few providers, while $35 \%$ of ocs disagreed that there are too few providers.

\section{Qualitative Results}

One hundred and eight ocs and 11 Hocs responded to at least one of the open-ended questions on the survey. Analysis of qualitative data from HOC and oc participants yielded 4 predominant themes: varied PC perceptions, resource constraints, interprofessional practice challenges, and intersectoral practice challenges (Table III). Of note, 2 themes (varied perceptions of PC and resource constraints) are aligned with the top 2 barriers identified by both Hocs and ocs on the quantitative part of the survey (patients' negative perceptions of PC and lack of time or competing priorities).

\section{DISCUSSION}

This study revealed significant differences between HOcs' and OCs' perspectives on the challenges to PC integration. Similar to previous reports, HOCs in our study felt that PC referral criteria are too strict ${ }^{12,15}$. This may stem from concerns about PC not accepting patients who are receiving chemotherapy or blood transfusions because, historically, these treatments have not always been offered in hospice 
TABLE I Demographics of the study participants

\begin{tabular}{|c|c|c|c|c|}
\hline \multirow[t]{2}{*}{ Variable } & \multicolumn{3}{|c|}{ Clinician type $[n(\%)]$} & \multirow{2}{*}{$\begin{array}{c}P \\
\text { Value }\end{array}$} \\
\hline & $\begin{array}{c}\text { Hematology } \\
\text { oncology }\end{array}$ & Oncology & Overall & \\
\hline Participants & 30 & 233 & 263 & \\
\hline Role & & & & 0.205 \\
\hline Administrative & $1(3)$ & $7(3)$ & $8(3)$ & \\
\hline Allied health & $4(13)$ & $44(21)$ & $48(18)$ & \\
\hline Nurse & $17(57)$ & $92(39)$ & $109(41)$ & \\
\hline Physician & $8(27)$ & $57(24)$ & $65(25)$ & \\
\hline Radiation therapist & 0 & $28(11)$ & $27(11)$ & \\
\hline Other & 0 & $5(2)$ & $5(2)$ & \\
\hline Gender & & & & 0.311 \\
\hline Women & $27(90)$ & $189(79)$ & $215(80)$ & \\
\hline Men & $3(10)$ & $49(20)$ & $52(19)$ & \\
\hline Others & 0 & $1(1)$ & $1(1)$ & \\
\hline Location & & & & 0.926 \\
\hline Tertiary centre & $27(90)$ & $147(63)$ & $182(66)$ & \\
\hline Community & $3(10)$ & $86(37)$ & $89(34)$ & \\
\hline Urban or rural & & & & 0.124 \\
\hline 0-9999 pop. & 0 & $8(3)$ & $8(3)$ & \\
\hline 10,000-49,999 рор. & 0 & $12(5)$ & $12(5)$ & \\
\hline 50,000-149,999 рор. & $3(10)$ & $57(24)$ & $60(23)$ & \\
\hline$\geq 150,000$ pop. & $27(90)$ & $150(64)$ & $177(63)$ & \\
\hline Not specified & 0 & $6(3)$ & $6(2)$ & \\
\hline Time in role & & & & 0.300 \\
\hline$\leq 10$ Years & $12(40)$ & $96(41)$ & $108(41)$ & \\
\hline$>10$ Years & $18(60)$ & $137(59)$ & 159 (59) & \\
\hline $\begin{array}{l}\text { Work with } \\
\text { patients with } \\
\text { advanced cancer }\end{array}$ & & & & 0.012 \\
\hline Rarely & $3(10)$ & $7(3)$ & $10(4)$ & \\
\hline Sometimes & $17(57)$ & $91(39)$ & $108(41)$ & \\
\hline Most of the time & $10(33)$ & $135(58)$ & $145(55)$ & \\
\hline \multicolumn{5}{|l|}{ Tumour group } \\
\hline All & & 6 & $6(2)$ & \\
\hline Breast & & $51(19)$ & $51(19)$ & \\
\hline CNS & & $7(3)$ & $7(3)$ & \\
\hline Gastrointestinal & & $37(14)$ & $37(14)$ & \\
\hline Genitourinary & & $14(5)$ & $14(5)$ & \\
\hline Gynecologic & & $16(6)$ & $16(6)$ & \\
\hline Head and neck & & $20(8)$ & $20(8)$ & \\
\hline Hematologic/BMT & $30(11)$ & & $30(11)$ & \\
\hline Lung & & $36(14)$ & $36(14)$ & \\
\hline Others & & $4(2)$ & $4(2)$ & \\
\hline Palliative & & $42(16)$ & $42(16)$ & \\
\hline
\end{tabular}

pop. = population; $\mathrm{CNS}=$ central nervous system; BMT = bone marrow transplant.

or while a patient is receiving $\mathrm{PC}^{26}$. Although the referral criteria for PC in Alberta do not specify that patients who are receiving palliative chemotherapy or who require transfusions for symptom control cannot be referred to PC, there may be misperceptions, on behalf of both hematology and PC clinicians, that these patients are typically not referred to PC until the chemotherapy or transfusions, or both, are stopped. However, there is growing recognition that if the intent is to relieve symptoms rather than to prolong life, it is both appropriate and acceptable to consider transfusions or chemotherapy for patients receiving concurrent $\mathrm{PC}^{27-29}$.

In their study examining attitudes and beliefs about supportive and PC referrals, Hui et al..$^{18}$ sent a survey to hematologic specialists $(n=120)$ and solid-tumour oncologists $(n=120)$. Of the respondents $(n=182,76 \%)$, the hematologic specialists were found to be less likely than the than solid-tumour oncologists to refer patients with newly diagnosed cancer to PC $(21 \%$ vs. $43 \%, \mathrm{p}=0.002)$. In addition, hematologic specialists indicated that they were less likely than solid-tumour oncologists to refer patients undergoing active primary treatment to PC $(24 \%$ vs. $40 \%, p=0.02)^{18}$. Similarly, Leblanc et al. ${ }^{20}$ conducted a multi-site, mixed-methods study to examine perceptions of PC among hematologic and solid-tumour oncologists. Participants $(n=74)$ completed a survey and underwent a semi-structured interview. Eight clinicians who treated both hematologic and solid-tumour malignancies were excluded, because the authors were interested in exploring the differences in perspectives between oncologists who specialized only in the care of patients with hematologic malignancies and those who specialized only in the care of patients with solid tumours. The final sample consisted of 43 solid-tumour oncologists and 23 hematologic oncologists. The authors found that while all solidtumour oncologists had previously referred a patient with advanced cancer to PC, $30 \%$ of the hematologic oncologists had never done so. Compared with hematologic oncologists, solid-tumour oncologists were also found to have more often referred patients with cancer without advanced disease to $\mathrm{PC}^{20}$. Although we did not assess these same referral practices, we found that $72 \%$ of HoCs reported that they were likely to recommend an early PC pathway to their patients. Moreover, $84 \%$ of HOCs disagreed with the statement that there is little benefit for their patients from PC services; only 1 HOC agreed with the statement.

The finding that HOCs reported they would have to personally make substantial changes to the way they practice in order to use earlier PC supports is notable and, to our knowledge, has not been previously reported in the literature. We can speculate that the unique aspects of both hematologic malignancies and their associated treatment, such as more curative intent therapies (for example, stemcell transplant) and more prognostic uncertainty than solid tumours, might have contributed to this perception ${ }^{15,20}$. In the earlier-mentioned study by Leblanc et al. ${ }^{20}$, the authors found that hematologic oncologists were more likely to describe PC as EOL care. In addition, hematologic oncologists also reported that there were differences in both disease- and treatment-related factors for hematologic malignancies compared with solid tumours, such as the availability of effective treatments even for patients with advanced or incurable disease. A focus on cure can be a barrier when PC is thought of solely as EOL care, as opposed to an added layer of holistic support for people living with serious illness ${ }^{30}$. A sense of mutual exclusivity might preclude the integration of PC into care, if HOCs feel that PC and disease-directed therapies cannot be delivered concurrently ${ }^{12,30}$. A number of respondents in our study 


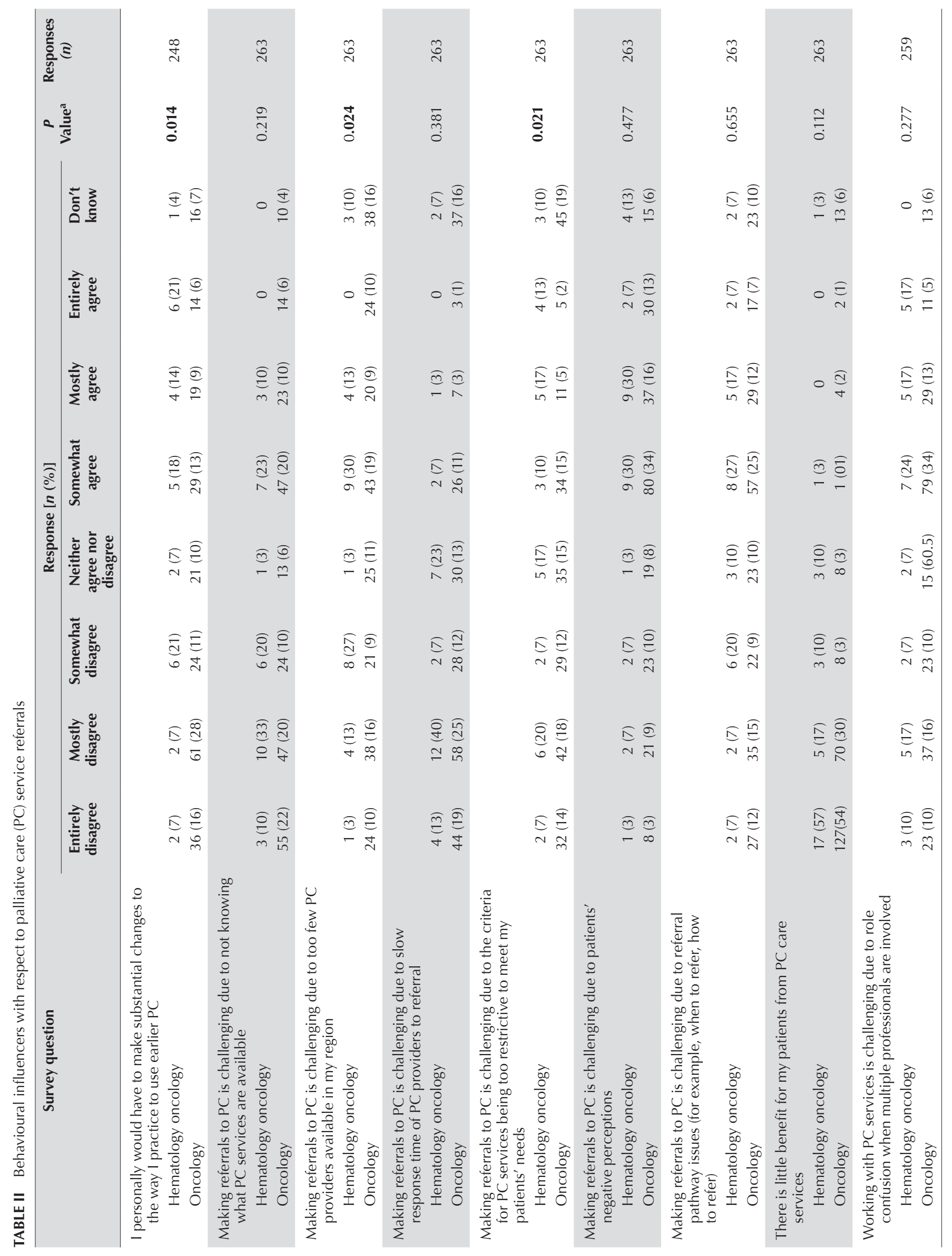


HEMATOLOGY ONCOLOGY PERSPECTIVES ABOUT INTEGRATING PALLIATIVE CARE, Booker et al. |

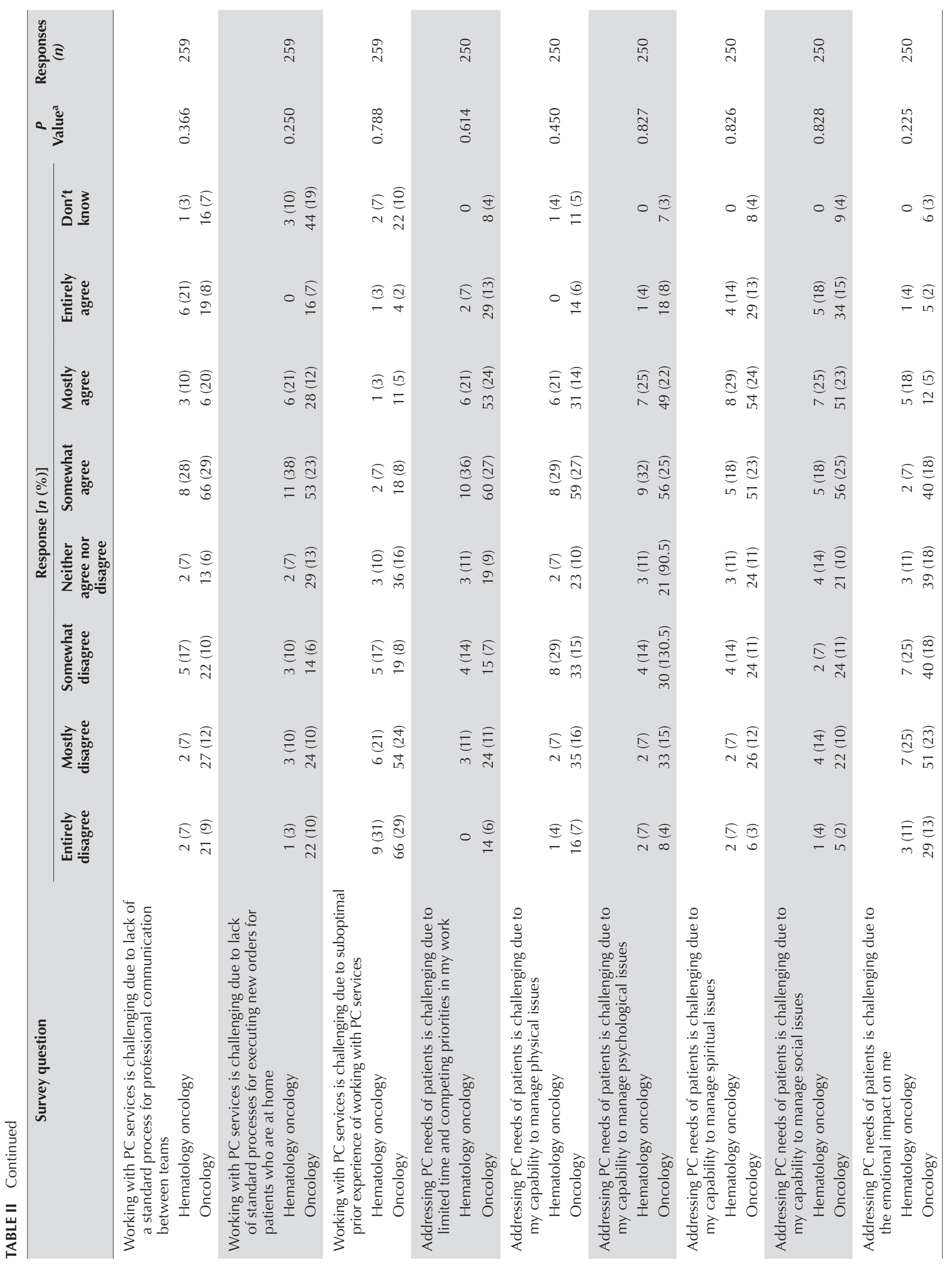




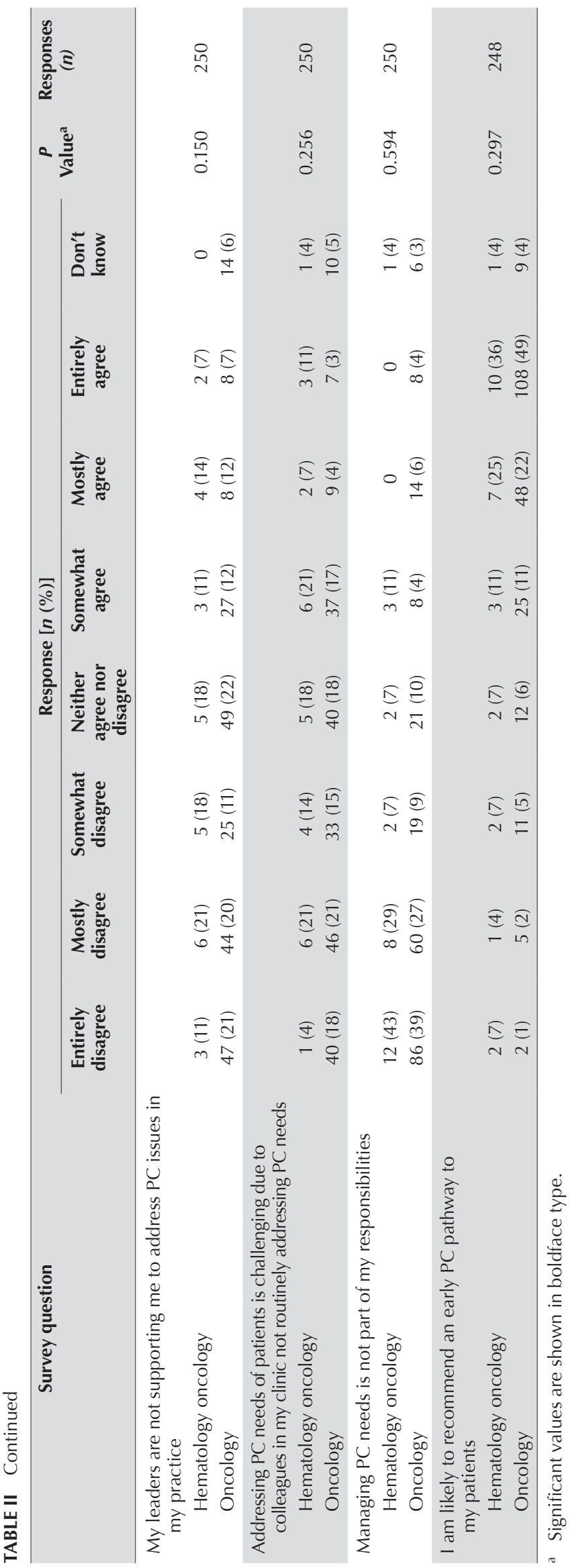

also commented on this sense of "either/or," where patients either continued with disease-directed therapy OR were referred to PC after exhausting all disease-directed options. Ongoing efforts aimed at educating patients, caregivers, and health care providers might help to erode the notion that PC is only for EOL ${ }^{16}$.

In our study, HOCs and oCs alike reported that making referrals to PC was challenging due to patients' negative perceptions of PC. Other authors have reported that oncology clinicians and patients with cancer might both misperceive PC as being synonymous with hospice or EOL care ${ }^{31-33}$. Such misperceptions may hinder clinicians' willingness to refer patients to PC, particularly early in the disease trajectory or alongside disease-directed therapy ${ }^{34,35}$. In the study by Hui et al. ${ }^{18}$, the authors found that hematologic specialists preferred the term "supportive care" to PC. Changing the name from PC might be particularly germane in malignant hematology, where diseases remain chemosensitive even when advanced or incurable and where clinicians and patients might find it difficult to reconcile ongoing disease-directed therapy, particularly if intended to be curative, with what many perceive to be EOL care.

In 2016, the American Society of Clinical Oncology published guidelines on the integration of PC in oncology and emphasized that PC is important for patients with advanced disease as well as those "facing high symptom burden"2 (p. 97). While the uptake of PC integration for those with advanced cancer has been steadily progressing, it is less clear that PC is being adopted for those with high symptom burden, particularly in curative-intent contexts. Patients with hematologic malignancies experience high symptom burden ${ }^{17,36,37}$ and thus would likely benefit from the integration of PC regardless of the stage of disease.

\section{Strengths and Limitations}

The involvement of a sizeable sample of multidisciplinary clinicians is a strength of this study, because many studies to date have predominantly involved physicians; however, the subsample of HOCs was small $(n=30)$, which represents a potential limitation. The sample size was proportionate to the percentage response rate for each tumour group. Given the small HoC sample size, differences based on clinician discipline of PC challenges could not be explored. The survey had been mailed out 3 times, and it is possible that participants could have completed the survey more than once. In addition, because the total number of oncology clinicians working with patients with advanced cancer in the province is unknown, the sample response rate is an estimate. There was no statistical adjustment for multiple testing. The use of Web-based surveys has been associated with limitations, particularly regarding external validity ${ }^{38}$. For example, self-selection bias could occur if participants feel compelled to respond to the survey because the topic is of interest to them ${ }^{38,39}$. The resultant sample might therefore not be representative of the larger population of interest, thereby limiting generalizability ${ }^{38,39}$.

\section{CONCLUSIONS}

This study revealed significant differences between HOCs' and ocs' perceptions of the integration of PC in cancer care. 
TABLE III Themes from qualitative data about integrating palliative care (PC) in oncology

\begin{tabular}{|c|c|}
\hline Theme & Supporting quotes \\
\hline \multicolumn{2}{|l|}{ Varied perceptions of $\mathrm{PC}$} \\
\hline $\begin{array}{l}\text { - Patients' negative views of PC } \\
\text { - Delaying referral until all disease-directed } \\
\text { treatments have ceased } \\
\text { - Need to educate patients, caregivers, and } \\
\text { clinicians about the potential benefits } \\
\text { of PC }\end{array}$ & $\begin{array}{l}\text { - "Palliative care means I'm dying or we're giving up." } \\
\text { - "[Referrals to PC are only pursued when] all other avenues have been exhausted." } \\
\text { - "Offer educational opportunities to patients and families to help them understand the } \\
\text { difference between palliative care and end-of-life care. Increase awareness of services } \\
\text { available to patients through staff education sessions explaining philosophy and criteria } \\
\text { - "Increase awareness that palliative care enhances quality of life, and living with cancer } \\
\text { - "is] not just for patients who are imminently dying." } \\
\text { patients and staff." }\end{array}$ \\
\hline \multicolumn{2}{|l|}{ Resource constraints } \\
\hline $\begin{array}{l}\text { - Insufficient time to address patients' } \\
\text { PC needs } \\
\text { - (Timely) access to PC services } \\
\text { - Availability of PC (including types of PC } \\
\text { resources available, as well as after-hours } \\
\text { availability) }\end{array}$ & $\begin{array}{l}\text { - "[PC] should be introduced early, but it does not seem possible to do this, as palliative } \\
\text { care is not really available to patients in the community or at the cancer centre until they } \\
\text { are } 2-4 \text { weeks from dying." } \\
\text { "Time constraints-patients deserve the time for addressing their concerns and palliative } \\
\text { care is complex and delicate. Our team is good at helping each other out when needed, } \\
\text { but this is not always possible." }\end{array}$ \\
\hline
\end{tabular}

Interprofessional practice challenges

- Integrating early PC would require significant changes to practice

- Lack of standard processes (how to integrate PC into care, shared care of patients, communication between PC and hematology)

- Mutual lack of understanding between PC and hematology oncology teams
- "[PC] will explain to patients what is available when we refer to them, but then they leave the ball in our court.... We need them to lead the way so [that] we have direction on how their involvement can work alongside palliative chemo for hematology patients. It shouldn't need to be one or the other; makes the transition very hard on patients."

- "[A] lack of understanding of relative roles, responsibilities, and communication between palliative care, primary care, and oncologist care"

- "Many oncologists do not refer patients to palliative services early enough. It's not a service for when 'there is nothing else we can do.' It's been well shown that palliative care improves quality of life and survival."

- "Sometimes there is a lack of understanding from palliative care practitioners that, although these patients might have failed treatment, they may still have good quality of life for a period of time with supportive care."

Intersectoral practice challenges

- Lack of standard processes

- Lack of communication between PC and oncology teams, hospital and community, urban and rural settings

- Need for support for primary care providers

- PC criteria too restrictive
- "Lack of a standard process for professional communication amongst all professionals and agencies involved is an issue...."

- "These patients are quite complex, and many family physicians have expressed a lack of confidence in caring for them, or are unable to provide the home visits or after hours advice or clinic assessments that they might require."

- "Our patients are reliant on transfusion support up until the very last days of their life, for several reasons, including management of breathlessness and fatigue (anemia), and to avoid having fatal bleeds (secondary to thrombocytopenia) as the primary cause of their demise. (There is a lot of fear from patients associated with this type of death.) Palliative care practitioners will often refuse to see patients or accept them into their programs until these transfusions are discontinued, making the time for support incredibly short."

- "The lack of home transfusions for palliative patients is a huge barrier at end of life and results in more hospital days and delayed transfer to hospice."

- "In BMT, we are so heavily involved in patients' care that they become confused as to whom to contact with questions or concerns. They are fearful of having to involve a new team in their care, they have become so comfortable with the BMT team that it becomes difficult to establish an entirely new therapeutic relationship with the palliative team."

$\mathrm{BMT}=$ bone marrow transplant.

The unique nature of hematologic malignancies represents a potential challenge to the integration of PC. Further research should explore why HOCs felt that integrating earlier PC supports would require significant changes to their personal practice and how to mitigate that. Ongoing education should emphasize that PC could be provided concurrently with disease-directed treatment. Finally, policy and funding reform that addresses increased availability of PC to allow less-strict referral criteria is warranted. Ensuring that patients with hematologic malignancies have access to concurrent PC has enormous potential to reduce symptom burden and optimize quality of life for patients and their caregivers.

\section{ACKNOWLEDGMENTS}

Financial support was provided by grants from Alberta Health (no. 007474), the Canadian Institutes of Health Research Partnerships for Health System Improvement for Cancer Control (HRC-154127), and the Alberta Cancer Foundation RK Dixon Family Award (no. 27265). 


\section{CONFLICT OF INTEREST DISCLOSURES}

We have read and understood Current Oncology's policy on disclosing conflicts of interest, and we declare that we have none.

\section{AUTHOR AFFILIATIONS}

*Department of Psychosocial Oncology, Tom Baker Cancer Centre, ${ }^{\dagger}$ Department of Community Health Sciences, University of Calgary, ${ }^{\ddagger}$ Department of Oncology, University of Calgary, ${ }^{\circledR}$ Department of Family Medicine, University of Calgary, and $\|_{\text {Department }}$ of Medicine, University of Calgary, Calgary, AB.

\section{REFERENCES}

1. Bakitas MA, Tosteson, TD, Li Z, et al. Early versus delayed initiation of concurrent palliative oncology care: patient outcomes in the ENABLE III randomized clinical trial. J Clin Oncol 2015;33:1438-45.

2. Ferrell BR, Temel JS, Temin S, et al. Integration of palliative care into standard oncology care: American Society of Clinical Oncology clinical practice guideline update.J Clin Oncol 2017;35:96-112.

3. Greer JA, Jackson VA, Meier DE, Temel JS. Early integration of palliative care services with standard oncology care for patients with advanced cancer. CA Cancer J Clin 2013;63:349-63.

4. Temel JS, Greer JA, Muzikansky A, et al. Early palliative care for patients with metastatic non-small-cell lung cancer. $N$ Engl J Med 2010;363:733-42.

5. Temel JS, Greer JA, El-Jawahri A, et al. Effects of early integrated palliative care in patients with lung and GI cancer: a randomized clinical trial. J Clin Oncol 2017;35:834-41.

6. Howell DA, Roman E, Cox H, et al. Destined to die in hospital? Systematic review and meta-analysis of place of death in haematological malignancy. BMC Palliat Care 2010;9:1-8.

7. Hui D, Didwaniva N, Vidal M, et al. Quality of end-of-life care in patients with hematologic malignancies: a retrospective cohort study. Cancer 2014;120:1572-8.

8. Leblanc TW,El-Jawahri A. When and why should patients with hematologic malignancies see a palliative care specialist? Hematology Am Soc Hematol Educ Program 2015;2015:475-8.

9. Selvaggi KJ, Vick JB, Jessell SA, Lister J, Abrahm JL, Bernacki R. Bridging the gap: a palliative care consultation in a hematological malignancy-bone marrow transplant unit. J Community Support Oncol 2014;12:50-5.

10. Davis MP, Bruera E, Morganstern D. Early integration of palliative and supportive care in the cancer continuum: challenges and opportunities. Am Soc Clin Oncol Educ Book 2013;2013:144-50.

11. Earp MA, Sinnarajah A, Kerba M, et al. Opportunity is the greatest barrier to providing palliative care to advanced colorectal cancer patients: a survey of oncology clinicians. Curr Oncol 2018;25:e480-5

12. McCaughan D, Roman E, Smith AG, et al. Palliative care specialists' perceptions concerning referral of haematology patients to their services: findings from a qualitative study. BMC Palliat Care 2018;17:33.

13. Zhi WI, Smith TJ. Early integration of palliative care into oncology: evidence, challenges and barriers. Ann Palliat Med 2015;4:122-31.

14. Levine DR, Baker JN, Wolfe J, Lehmann LE, Ullrich C. Strange bedfellows no more: how integrated stem-cell transplantation and palliative care programs can work together to improve end-of-life care. J Oncol Pract 2017;13:569-77.

15. Odejide OO, Salas Coronado DY, Watts CD, Wright AA, Abel GA. End-of-life care for blood cancers: a series of focus groups with hematologic oncologists. J Oncol Pract 2014; 10:e396-e403.

16. Kaasa S, Loge JH, Aapro M, et al. Integration of oncology and palliative care: a Lancet Oncology Commission. Lancet Oncol 2018;19:e588-e653.

17. Zimmermann C, Yuen D, Mischitelle A, et al. Symptom burden and supportive care in patients with acute leukemia Leuk Res 2013;37:731-6.

18. Hui D, Bansal S, Park, M, et al. Differences in attitudes and beliefs toward end-of-life care between hematologic and solid tumor oncology specialists. Ann Oncol 2015;26:1440-6.

19. El-Jawahri A, Leblanc TW, Burns LJ, et al. What do transplant physicians think about palliative care? A national survey study. Cancer 2018;124:4556-66.

20. Leblanc TW, O'Donnell JD, Crowley-Matoka M, et al. Perceptions of palliative care among hematologic malignancy specialists: a mixed-methods study.J Oncol Pract 2015;11:e230-8.

21. Palliative Care Early and Systematic (PaCES). Palliative care early and systematic (PaCES) [Web page]. [Available online at www.pacesproject.ca; cited 29 November 2019]

22. Watanabe S, Dunn S, Earp M, et al. Barriers to providing palliative care to patients with advanced cancer: a province-wide survey of oncology clinicians' perceptions. JClin Oncol 2018;36:88.

23. Vanderbilt University. REDCap [Web page]. [Available online at: https://redcap.vanderbilt.edu; cited 29 November 2019]

24. Hsieh HF, Shannon SE. Three approaches to qualitative content analysis. Qual Health Res 2005;15:1277-88.

25. Elo S, Kyngas $H$. The qualitative content analysis process. J Adv Nurs 2007;62:107-15.

26. Leblanc TW, Egan PC, Olszewski AJ. Transfusion dependence, use of hospice services, and quality of end-of-life care in leukemia. Blood 2018;132:717-26.

27. Leblanc TW. Palliative care and hematologic malignancies: old dog, new tricks? J Oncol Pract 2014;10:e404-7.

28. Leblanc TW, Egan PC, Olszewski AJ. Transfusion dependence, use of hospice services, and quality of life care in leukemia. Blood 2018;132:717-26.

29. Mannis GN, McNey LM, Gupta NK, Gross DM. The transfusion tether: bridging the gap between end-stage hematologic malignancies and optimal end-of-life care. Am J Hematol 2016; 91:364-5.

30. Leblanc TW, El-Jawahri A. Hemato-oncology and palliative care teams: is it time for an integrated approach to patient care? Curr Opin Support Palliat Care 2018;12:530-7.

31. Collins A, McLachlan SA, Philip J. Communication about palliative care: a phenomenological study exploring patient views and responses to its discussion. Palliat Med 2018;32:133-42.

32. Mahon MM, McAuley WJ. Oncology nurses' personal understandings about palliative care. Oncol Nurs Forum 2010; 37:E141-50.

33. Zimmermann C, Swami N, Krzyzanowska M, et al. Perceptions of palliative care among patients with advanced cancer and their caregivers. CMAJ 2016;188:E217-27.

34. Bakitas M, Lyons KD, Hegel MT, Ahles T. Oncologists' perspectives on concurrent palliative care in a National Cancer Institute-designated comprehensive cancer centre. Pall Support Care 2013;11:415-23.

35. Jordan K, Aapro M, Kaasa S, et al. European Society of Medical Oncology (ESMO) position paper on supportive and palliative care. Ann Oncol 2018;29:36-43.

36. Hochman MJ, Yu Y, Wolf SP, Samsa GP, Kamal AH, LeBlanc TW. Comparing the palliative care needs of patients with hematologic and solid malignancies. JPain Symptom Manage 2017; 55:82-8

37. Manitta V, Zordan R, Cole-Sinclair M, Nandurkar, H, Philip J. The symptom burden of patients with hematological malignancy: a cross-sectional observation study. J Pain Symptom Manage 2011;42:432-42.

38. Eysenbach G, Wyatt J. Using the Internet for surveys and health research. J Med Internet Res 2002;4:E13.

39. Wright KB. Researching Internet-based populations: advantages and disadvantages of online survey research, online questionnaire authoring software packages, and Web survey services. J Comput Mediat Commun 2005;10. [Available online at: https://academic.oup.com/jcmc/article/10/3/ JCMC1034/4614509; cited 29 November 2019] 